\title{
Perfil socioeconômico dos beneficiários do Programa Bolsa Família no Munícipio de Pato Branco/PR
}

Caroline Viganó ${ }^{1}$

Marcio Gazolla²

\begin{abstract}
Resumo
Os programas de transferência condicionada de renda são políticas sociais que visam combater e reduzir a pobreza no Brasil por meio de estratégias de prevenção, enfrentamento e suavização. Este artigo tem por objetivo analisar o perfil dos beneficiários do Programa Bolsa Família (PBF), no Município de Pato Branco/PR e, correlacionar este com as condições socioeconômicas de vida das famílias, utilizando dados secundários do Cadastro Único para Programas Sociais do Governo Federal (CadÚnico). O estudo indica que apesar do município apresentar indicadores positivos de desenvolvimento, ainda há famílias vulneráveis localmente, em torno de 6,50\% da população. Estes beneficiários do PBF caracterizam-se por residirem nos espaços urbanos, são de cor branca e com grande representatividade feminina. Além disso, apresentam baixa disponibilidade de recursos financeiros e falta de trabalho remunerado há algum tempo, o que contribuí como a situação de vulnerabilidade social. Para romper com o círculo da pobreza há necessidades de políticas públicas integradas e mais profundas, além destas terem como objetivo eliminar as causas das privações de liberdades dessa população.
\end{abstract}

Palavras-chave: Pobreza; Programa Bolsa Família; Política social; Desenvolvimento local e regional.

\section{Socioeconomic profile of the beneficiaries of the Bolsa Família Program in the municipality of Pato Branco/PR}

\begin{abstract}
Conditional cash transfer programs are social policies that aim to combat and reduce poverty in Brazil through prevention, coping and mitigation strategies. This article aims to analyze the profile of the beneficiaries of the Bolsa Família Program (PBF) in the municipality of Pato Branco / PR and to correlate this with the socioeconomic conditions of life of the families, using secondary data from the Single Registry for Social Programs of the Federal Government (CadÚnico). The study indicates that although the municipality has positive development indicators, there are still vulnerable families locally, around $6.50 \%$ of the population. These beneficiaries of the PBF, are characterized by living in urban spaces, are white in color and with great female representation. In addition, they have low availability of financial resources and lack of paid work for some time, which contributed to the situation of social vulnerability. In order to break the circle of poverty, there are needs for more integrated and deeper public policies, in addition to the objective of eliminating the causes of deprivation of freedoms for this population.
\end{abstract}

Keywords: Poverty; Bolsa Família Program; Social policy; Local and regional development.

\footnotetext{
${ }^{1}$ Mestranda do Programa de Pós-Graduação em Desenvolvimento Regional (PPGDR) da Universidade Tecnológica Federal do Paraná (UTFPR). vigano.carol@gmail.com

2 Doutor em desenvolvimento Rural (UFRGS). Professor do Programa de Pós-Graduação em Desenvolvimento Regional (PPGDR) da Universidade Tecnológica Federal do Paraná (UTFPR). marciogazolla@utfpr.edu.br
} 


\section{Introdução}

A partir do século XXI, o Brasil vem apresentando considerável redução no nível de pobreza e desigualdade social, de 47\% em 1990, para 22\% em 2012 (PNUD, 2013). O crescimento do emprego formal, aumento significativos do salário mínimo, estabilização macroeconômica dos anos 1990 e o estabelecimento de políticas sociais contribuíram para melhorar a renda de muitas pessoas que se encontravam em situação de pobreza ou pobreza extrema (SILVA et al., 2017).

A criação de programas federais de transferência de renda foi uma das mais importantes ações de da área de política social, estando inseridas no 'pacote' de programas sociais que são direcionados à população mais vulnerável do país (IPEA, 2006). Conforme ressaltam Silva, Yasbek e Di Giovani (2007, p.12) "os programas de transferência de renda tornaram-se o "carro-chefe" da rede de proteção social brasileira".

Nesse sentido, os Programas de Transferência de Renda (PTR) propõem o alívio da pobreza de brasileiros por meio de contrapartidas que pretendem aumentar "a demanda por serviços sociais como saúde e educação e ampliar o acesso da população mais pobre a direitos sociais básicos, incentivando expansões e melhorias na oferta desses serviços" (MEDEIROS; BRITTO; SOARES, 2007, p.12).

Estes princípios acima mencionados, vão na direção preconizada por Sen (2000) que afirma que para as pessoas possuírem um desenvolvimento humano com liberdades substantivas, o Estado deve garantir liberdades políticas, facilidades econômicas, oportunidades sociais, garantias de transparência e segurança protetora. Neste último item, enquadram-se as políticas de proteção social, como é o caso do Programa Bolsa Família (PBF).

O PBF possui impactos sociais e econômicos locais junto a população mais pobre dos municípios e regiões, mas também repercute na movimentação da economia já que estes recursos são injetados em vários setores produtivos e econômicos, fomentando assim o desenvolvimento local (BOISER, 2001). Neste sentido, manter avaliações atualizadas da política, em níveis regionais e mesmo locais, é fundamental, de forma a conhecer-se sua dinâmica e prover de subsídios os gestores e policy makers (CAMPELO; NERI, 2013).

Dessa forma, o objetivo deste artigo é analisar o perfil dos beneficiários do Programa Bolsa Família no Município de Pato Branco/PR e correlacionar com as condições socioeconômicas de vida das famílias. Para atingir este objetivo, analisa-se os dados secundários do Cadastro Único para Programas Sociais do Governo Federal (CadÚnico), disponibilizados pela Secretaria 
Municipal de Assistência Social. Os dados referem-se ao total de famílias beneficiadas pelo PBF atualizados até o mês de junho de 2018.

Este trabalho está estruturado em duas seções principais, além desta introdução e das considerações finais. Na primeira parte resgata-se o histórico da construção das políticas sociais de transferência de renda no Brasil. Na segunda apresenta-se os principais resultados da pesquisa a partir dos dados contidos no CadÚnico de Pato Branco/PR.

\section{A construção histórica das políticas de transferência de renda no Brasil}

No Brasil os marcos iniciais dos programas de transferência de renda surgiram a partir da década de 1990, se apresentando como um sistema de proteção social com o objetivo de combater a pobreza e reduzir a desigualdade social no país (MARTINS, 2013). A partir de então, no ano de 1991, Eduardo Suplicy propunha a criação do Programa de Garantia de Renda Mínima (PGRM). Esse programa estabelecia o recebimento de uma renda mínima pela população brasileira com idade superior a 25 anos e com rendimentos limitados. Apesar de ter sido aprovado pelo Governo Federal o programa não saiu do papel (SILVA, 2007; MARTINS 2013).

No ano de 1995 iniciaram-se as experiências municipais de transferência de renda no Estado de São Paulo e Distrito Federal. A expansão desses programas deu-se partir de 2001, por meio da criação dos programas federais: Bolsa Escola e Bolsa Alimentação (SILVA, 2007). O Programa Bolsa Escola (PBE) tinha o propósito de aumentar a frequência escolar de crianças inseridas em famílias que possuíam, na época, renda mensal inferior a $R \$ 100,00$. (DUARTES; SAMPAIO; SAMPAIO, 2009; BICHIR, 2010). Já o Bolsa Alimentação propunha complementar a renda familiar e proporcionar melhor alimentação as famílias de baixa renda (MDS, 2002).

Em janeiro de 2002, ainda no governo FHC, é instituído o programa Auxílio Gás, que conforme o Art. 1 do Decreto 4.102/2002 seria "destinado a subsidiar o preço do gás liquefeito de petróleo às famílias de baixa renda". O valor do benefício recebido pelas famílias era de R\$ 7,50 pagos bimestralmente ao responsável familiar (BRASIL, 2002).

Ao assumir o governo no ano de 2003, o então Presidente Luiz Inácio Lula da Silva cria o Programa Bolsa Família (PBF), a partir da junção dos programas acima citados, que foram gradualmente integrados em um único programa federal. Lula consolidou e procurou expandir a rede de programas herdados do governo FHC (BICHIR, 2010).

O Programa Bolsa Família (PBF) é hoje o maior programa de transferência de renda condicionada no mundo, tornou-se uma das principais ações da política social do Estado, 
alcançando 13,7 milhões de famílias ${ }^{3}$ (COSTAZI; FAGUNDES, 2010; MDS, 2018). O PBF foi criado com o objetivo de "promover a redução da pobreza e a sua superação no médio e longo prazo, através da transferência de renda e da criação de oportunidades de inserção socioeconômica para as famílias beneficiárias" (SILVA et al., 2017. p. 86). O programa prioriza como público alvo de suas ações as famílias em situação de extrema pobreza e pobreza, considerando sua renda per capita de $\mathrm{R} \$ 85,00$ ou de $\mathrm{R} \$ 85,01$ a $\mathrm{R} \$ 170,00$ desde que possuam crianças ou adolescentes de 0 a 17 anos (MDS, 2018).

Além da transferência monetária, o PBF apresenta um conjunto de ações que podem ser desenvolvidas no âmbito da educação, saúde e trabalho. Possibilita que crianças e jovens tenham acesso à escola e saúde e os adultos a capacitação profissional, micro crédito e acompanhamento gestacional (SILVA, 2007). Essas ações são também chamadas de condicionalidades ou contrapartidas - requisitos que as famílias devem cumprir para continuar recebendo o auxílio. As famílias devem ser responsáveis por manter as crianças e adolescentes frequentando a escola e cumprir com os cuidados básicos de saúde; seguir o calendário de vacinação das crianças e a agenda de pré e pós-natal para gestantes e nutrizes (BICHIR, 2010).

\section{Programa Bolsa Família do Município de Pato Branco}

\subsection{Caracterização dos beneficiários}

De acordo com a Prefeitura Municipal (2018), Pato Branco é uma das cidades mais desenvolvidas do país. Está localizada na Região Sudoeste do Paraná e ocupa atualmente a 4o posição no Índice Firjan de Desenvolvimento Municipal (IFDM), com destaque para a saúde, tecnologia, educação e geração de emprego e renda.

Dados publicados no Atlas de Desenvolvimento Humano do Brasil (2013) revelam que o município apresenta grande evolução nos Índices de Desenvolvimento Humano Municipal (IDHM). O Gráfico 1 denota que entre os anos de 1991 a 2000, o IDHM passou de 0,560 para 0,717 em 2000, apresentando um crescimento de $28,04 \%$. No que se refere à distância entre o IDHM do município e o limite máximo do índice que é 1, esse, foi reduzido em $64,32 \%$.

Em uma análise mais atual, entre os anos de 1991 a 2010 o IDHM do município passou de 0,560\% para $0,782 \%$ em 2010 , um salto de $0,22 \%$ em quase duas décadas. Isso implica em uma

\footnotetext{
${ }^{3}$ Considerando benefícios concedidos até maio de 2018.
} 
taxa de crescimento de 39,64\% para o município e 47\% para a o Estado do Paraná (ADHB, 2013). No que tange o indicador renda, segundo a mesma fonte, entre os anos de 1991 a 2010 a proporção de pessoas extremamente pobres com renda per capita igual ou inferior a $R \$ 70,00$ mensais reduziu-se consideravelmente (Tabela 1).

Gráfico 1 - Evolução do Índice de Desenvolvimento Humano Municipal de Pato Branco

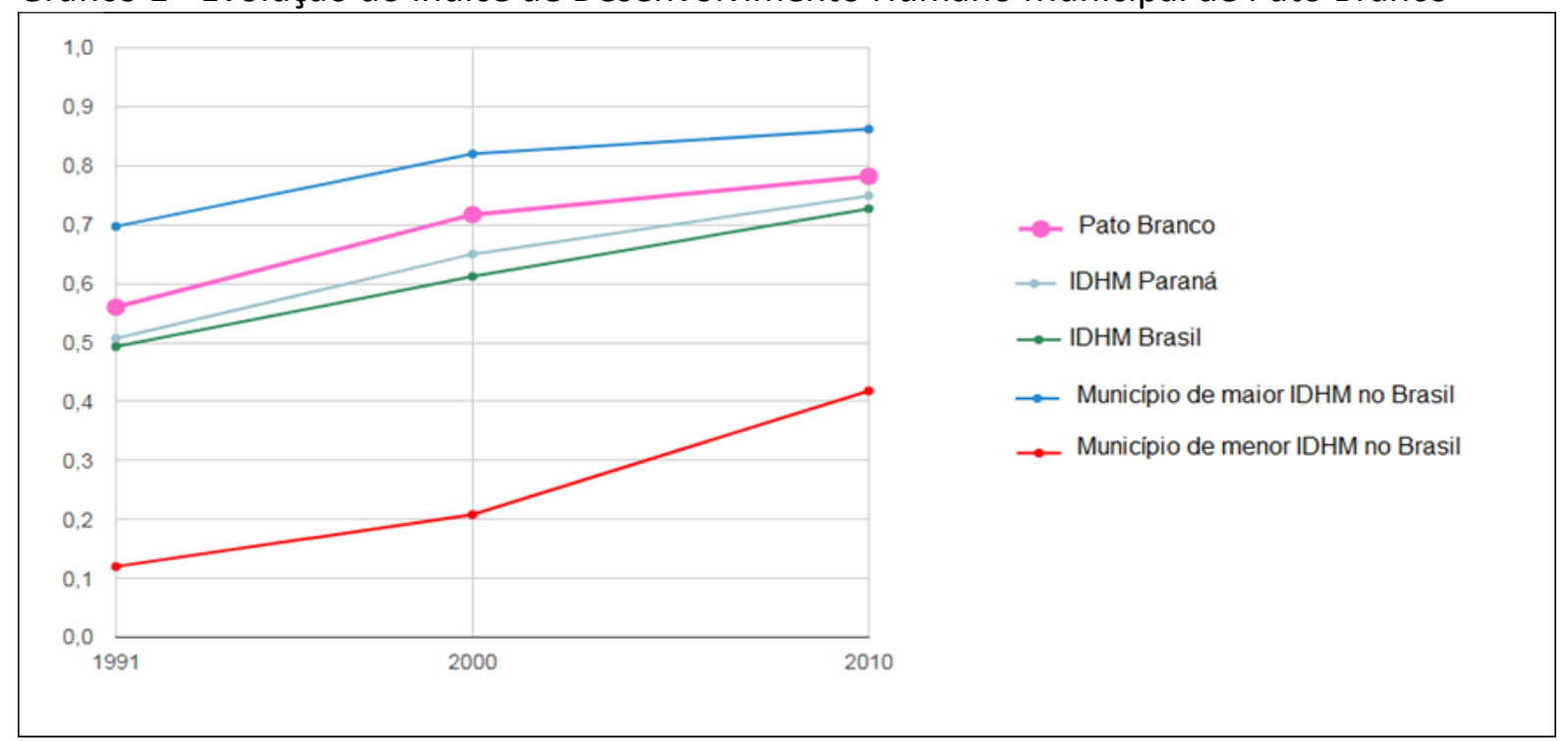

Fonte: Atlas do Desenvolvimento Humano no Brasil (2013).

Em 1991 o município contava com 8,62\% da população nessas condições, em 2000 reduzir para 2,73\% e em 2010 para 1,57\%. Ademais, os últimos dados apresentados referem-se ao ano de 2010 , apontando 3,71\% de pessoas em condição de pobreza e 13,67\% de pessoas vulneráveis a pobreza. Em relação ao Índice de Gini, que mede a concentração de renda (onde 0 representa igualdade e 1 desigualdade, em que apenas uma pessoa detém toda a riqueza), o município tem apresentado nas últimas duas décadas bons resultados; no ano de 1991 com 0,58\% e em 2010 0,51\%, um diferença de $0,07 \%$ no período referido. (ADHB, 2013).

Tabela 1 - Renda, pobreza e desigualdade no munícipio de Pato Branco/PR

\begin{tabular}{lrrr} 
& 1991 & 2000 & 2010 \\
\hline Renda per capita & $\mathrm{R} \$ 506,94$ & $\mathrm{R} \$ 736,20$ & $\mathrm{R} \$ 1.013,22$ \\
\% de extremamente pobres & 8,62 & 2,73 & 1,57 \\
\% de pobres & 26,23 & 11,68 & 3,71 \\
Índice de Gini & 0,58 & 0,56 & 0,51 \\
\hline
\end{tabular}

Fonte: Atlas do Desenvolvimento Humano no Brasil (2013).

Apesar dos dados do município apresentar uma evolução positiva em seus indicadores de desenvolvimento regional como evidenciado acima, ainda há famílias vulneráveis localmente. 
Com uma população de aproximadamente 72.500 habitantes, os dados de junho de 2018 apontam que 1.952 famílias foram beneficiadas pelo Programa Bolsa Família, equivalendo a 6,50\% da população total do município. Nesse mesmo mês, $\mathrm{R} \$ 236.060,00$ foram transferidos às famílias cadastradas (MDS, 2018). Estes últimos dados apresentados evidenciam uma situação contrária às estatísticas oficiais, pois mostram que o percentual de famílias pobres é bem maior do que o presente nestas.

A cobertura do programa no município é de $73,74 \%$ em relação à estimativa de famílias pobres. Essa estimativa é calculada de acordo com os dados atuais do Censo Demográfico. Esses dados retratam que o município está abaixo da meta de atendimento do programa, sendo a gestão municipal responsável por promover ações de busca ativa para localizar famílias que estão no perfil do programa, mas que ainda não foram cadastradas, além da manutenção e atualização cadastral dos beneficiários (MDS, 2018).

O Programa Bolsa Família atende o total de 6.334 pessoas no município. A distribuição desses beneficiários é de predominância urbana, 5.984 beneficiários (94,47\%), enquanto 350 beneficiários (5,53\%) residem na área rural (Tabela 2 ).

Tabela 2 - Distribuição das pessoas beneficiárias do PBF por localidade

\begin{tabular}{lcc}
\hline Localidade & № de pessoas & Percentual (\%) \\
\hline Urbano & 5.984 & 94,47 \\
Rural & 350 & 5,53 \\
\hline Total & $\mathbf{6 . 3 3 4}$ & $\mathbf{1 0 0 \%}$ \\
\hline
\end{tabular}

Fonte: Elaboração própria a partir do Cadastro Único (2018).

Esses dados se justificam devido à predominância da população residir em áreas urbanizadas, sendo que do total dos habitantes do munícipio apenas 4.279 residem no rural. Desse modo, as discussões de De Paula e Júnior (2005), afirmam que a migração campo-cidade deve ser entendida como forma de exclusão dos pobres que não encontram possibilidades de sobrevivência no lugar de origem nem oportunidades no lugar de destino. E como já apontado por Brito e Souza (2005), são fatores de expulsão e fatores de atração associados com o modo de produção capitalista que desemprega no campo e cria esperança de trabalho na cidade, formando situações de vulnerabilidade social no âmbito urbano.

Verifica-se na Tabela 3 a distribuição das famílias beneficiárias do PBF por bairros do município. Em se tratando da área urbana, as regiões Oeste e Sul possuem maior número de pessoas beneficiadas pelo PBF. O Bairro São João conta com 847 pessoas, representando 14,15\% dos beneficiários urbanos. Em segundo lugar o Bairro Alvorada com 745 pessoas (12,45\%). Já os 
bairros com o menor número de beneficiários são: Amadori, BR 158 e Brasília (0,03\%), localizados na região Oeste com maior aproximação central e na região Leste da cidade. De maneira geral nota-se uma predominância das famílias beneficiárias do PBF nas áreas urbanas do sul do município, dado a existências de bairros mais fragilizados socialmente do que os existentes no eixo Centro-Norte da cidade.

Tabela 3 - Distribuição das pessoas beneficiárias do PBF, por localidade urbana/bairros

\begin{tabular}{|c|c|c|c|c|c|c|c|}
\hline Bairros & $\%$ & Bairro & $\%$ & Bairros & $\%$ & Bairros & $\%$ \\
\hline Aeroporto & 0,62 & Centro & 1,94 & N. Horizonte & 4,29 & São João & 14,15 \\
\hline Alto da Gloria & 1,49 & Cristo Rei & 1,62 & Pagnoncelli & 0,15 & São Luiz & 0,40 \\
\hline Alvorada & 12,45 & Encruzilhada & 0,37 & Parq. do Som & 0,18 & São Roque & 2,66 \\
\hline Amadori & 0,03 & Fraron & 0,97 & Pinheirinho & 2,64 & São Vicente & 0,65 \\
\hline Anchieta & 0,17 & Gralha Azul & 3,24 & Pinheiros & 0,05 & Sudoeste & 6,65 \\
\hline Bancários & 0,69 & Industrial & 3,43 & Planalto & 5,72 & Tr. Catani & 0,05 \\
\hline Bela Vista & 3,51 & Jd. Floresta & 5,61 & Sambugaro & 0,30 & T. Guarani & 0,15 \\
\hline Bonatto & 2,61 & Jd. Américas & 0,23 & Santa Fé & 0,12 & Veneza & 1,19 \\
\hline Bortot & 0,75 & Jd. Primavera & 0,23 & Sta. Terezinha & 0,60 & Vila Brasil & 0,07 \\
\hline BR 158 & 0,03 & La Salle & 0,95 & Sto. Antônio & 2,91 & Vila Esperança & 1,77 \\
\hline Brasília & 0,03 & Menino Deu & 0,80 & São Cristovão & 9,09 & Vila Isabel & 0,33 \\
\hline Cadorin & 0,12 & Morumbi & 2,52 & São Francisco & 1,25 & Vila Verde & 0,22 \\
\hline
\end{tabular}

Fonte: Elaboração própria a partir do Cadastro Único (2018).

Quanto à localização de beneficiários no meio rural, a Tabela 4 apresenta sua localização, divididos por comunidades. Os dados apontam que São Roque do Chopim com 96 pessoas atendidas é a comunidade com o maior número de beneficiários, representando 27,43\%. Em seguida, "Interior" com 37 beneficiários (10,57\%). Com apenas 5 pessoas atendidas, a Linha Damasceno é a comunidade com o menor número de beneficiários na área rural (1,43\%).

Tabela 4 - Distribuição das pessoas beneficiárias do PBF, por localidade rural e comunidade

\begin{tabular}{lrr|lrr}
\hline Comunidade & No Pessoas & (\%) & Comunidade & № Pessoas & (\%) \\
\hline Fazenda da Barra & 35 & 10,00 & Linha São Caetano & 2,00 \\
Independência & 18 & 5,14 & Quebra Freio & 6 & 1,71 \\
Interior & 37 & 10,57 & S. Miguel Cachoerinha & 17 & 4,86 \\
Linha Damasceno & 5 & 1,43 & S. Pedro de Alcantra & 13 & 3,71 \\
Linha Esperança & 7 & 2,00 & São Roque do Chopim & 96 & 27,43 \\
Linha Marinelo & 6 & 1,71 & Sede Dom Carlos & 21 & 6,00 \\
Linha N. Sra. Carmo & 4 & 1,14 & Vila São Pedro & 16 & 4,57 \\
Passo da Ilha & 14 & 4,00 & Bom Retiro & 35 & 10,00 \\
Passo da Pedra & 13 & 3,71 & & $\mathbf{3 5 0}$ & $\mathbf{5 , 3 5 \%}$ \\
\hline Total de beneficiários rural & \multicolumn{7}{l}{}
\end{tabular}

Fonte: Elaboração própria a partir do Cadastro Único (2018). 
No que tange a distribuição dos beneficiários por sexo, constata-se que a maioria é do sexo feminino, são 3.722 mulheres $(58,72 \%)$ beneficiárias pelo PBF que se encontra em situação de pobreza (Tabela 5). Nota-se uma diferença razoável de apenas 17,52\% em relação ao sexo masculino que detém 2.612 pessoas (41,24\%). De acordo com o MDS (2014), das famílias brasileiras beneficiadas, 93\% são as mulheres as titulares do cartão do Bolsa Família, muitas vezes, são as principais responsáveis pelos cuidados familiares e dos filhos.

Molyneux (2006) demonstra com seu estudo sobre programas de transferência de renda na América Latina, que o Programa Oportunidades do México (semelhante ao PBF) também são as mulheres as responsáveis familiares quanto ao recebimento dos recursos. A autora afirma que isso é importante na perspectiva que as mulheres agem principalmente no interesse de seus filhos, a fim de melhor cumprir com as responsabilidades maternas, garantindo melhoria nas chances de vida, estado nutricional e educação.

Pressupõe-se que são as mulheres que cuidam do lar e da família, utilizam o recurso de forma mais eficiente e atendem as prioridades familiares, investindo no bem-estar dos filhos, enquanto os homens tendem a gastar os recursos com coisas supérfluas e para o consumo próprio. Não obstante, Santos et al (2017) ressalta ainda a hipótese do aumento de famílias chefiadas por mulheres jovens e solteiras e que, por vezes, possuem limitações em relação aos mercados de trabalho advindas da maternidade.

A Tabela 5 ainda evidencia a estratificação por cor/raça dos beneficiários. Os dados apontam que a predominância do município é de beneficiários da cor branca $(62,65 \%)$; em seguida de pessoas da cor parda $(35,10 \%)$, seguido pelos pretos $(1,44 \%)$, reafirmando o que é apresentado na literatura.

Tabela 5 - Distribuição das pessoas beneficiárias do PBF, por cor/raça e sexo.

\begin{tabular}{lrr|crr}
\hline Cor/raça & № de pessoas & $\%$ & Sexo & № de pessoas & $\%$ \\
\hline Branca & 3.968 & 62,65 & Masculino & 2.612 & 41,24 \\
Preto & 91 & 1,44 & Feminino & 3.722 & 58,76 \\
Amarela & 42 & 0,66 & & & \\
Parda & 2.223 & 35,10 & & & \\
Indígena & 7 & 0,11 & & & \\
Sem inf. & 3 & 0,05 & & $\mathbf{1 0 0 \%}$ \\
\hline Total & $\mathbf{6 . 3 3 4}$ & $\mathbf{1 0 0 \%}$ & Total & $\mathbf{6 . 3 3 4}$ & \\
\hline
\end{tabular}

Fonte: Elaboração própria a partir do Cadastro Único (2018).

Consoante com estudo de Melo (2005), em que retrata dados sobre a pobreza no Brasil, a autora afirma que famílias pobres e indigentes se distribuem de forma semelhante na sociedade brasileira. Há uma maior concentração de negros e de pobres na região Norte e 
Nordeste do país e, na Região Sul, há predominância de brancos (75\%), seguido por pardos (20\%) e pretos (4,5\%). Igualmente apontado por Souza e Couto (2015), os beneficiários brancos no estado do Paraná se apresentam em maior número, enquanto na Bahia a predominância é de beneficiários da cor parda $(75,66 \%)$, seguidos por pretos (12,80\%). A autora afirma que esse fato se deve por Bahia ser um estado que detém maior proporção de negros na sua população (76,3\%), enquanto o Paraná uma maior proporção de brancos (70,3\%).

No entanto, esses dados não devem ser generalizados, pois características opostas também são encontradas no Sul do país. Medeiros e Santos (2016) revelam que a predominância no município de Chapecó/SC é de beneficiários negros e pardos (71,72\%). De igual modo, no âmbito rural do Paraná, Santa Catarina e Rio Grande do Sul, como tratado por Silva et al (2017).

A Tabela 6 traz a escolaridade dos indivíduos do PBF. Retrata que das 1.952 famílias beneficiárias do PBF, sua maioria é composta por representantes que possuem baixa instrução escolar, tendo cursado apenas o ensino fundamental (62,03\%). Por esse ângulo, Silva et al (2017) argumentam que a baixa escolaridade dessa população maximiza as dificuldades de inserção nos mercados de trabalho, restando ocupações informais e de baixa remuneração. Já os responsáveis familiares que possuem escolaridade até o ensino médio são 620 (31,76\%); não obstante, o ensino superior é o nível escolar com menor número de representantes, são apenas 15 (0,76\%).

Em confrontação com dados em nível nacional, um estudo realizado por Costanzi e Fagundes (2010) apresenta pouca diferença na predominância de escolaridade dos representantes familiares do PBF, sendo que $77,4 \%$ dos responsáveis não possuem ensino fundamental completo e, apenas $11,1 \%$ possuem o ensino médio completo. Neste sentido, o autor realiza uma análise a garantia de emprego formal: “[...] o baixo nível de escolaridade desses responsáveis, traz implicações negativas do ponto de vista de inserção no mercado de trabalho, em especial, no mercado formal" (p. 267).

Tabela 6 - Distribuição dos responsáveis familiares beneficiados do PBF, por curso mais elevado cursado

\begin{tabular}{lrr}
\hline Escolaridade & No de famílias & Percentual (\%) \\
\hline Pré-Escola & 0 & 0,00 \\
Ensino Fundamental & 1.211 & 62,03 \\
Ensino Médio & 620 & 31,76 \\
Ensino Superior & 15 & 0,76 \\
Sem Informação & 106 & 5,43 \\
\hline Total & $\mathbf{1 . 9 5 2}$ & $\mathbf{1 0 0 \%}$ \\
\hline
\end{tabular}

Fonte: Elaboração própria a partir do Cadastro Único (2018). 
A partir da perspectiva que nos é colocada por Amartya Sen (2000), podemos pensar a educação sob a lógica de o indivíduo obter meios para ampliar suas liberdades, eliminar barreiras e buscar por oportunidades reais na sociedade, não apenas economicamente, mas de dignidade humana. Nesse sentido, é evidente a importância das condicionalidades - que devem ser cumpridas pelos beneficiários do PBF, sendo uma delas o acesso frequente de crianças e préadolescentes as instituições de ensino oferecidas pelo Estado, para que as gerações futuras possuam um capital educacional diferenciado.

A Tabela 7 demonstra a faixa etária das pessoas que compõe as famílias beneficiárias pela política. A distribuição dos beneficiários do PBF que compõem as famílias denota uma maior concentração de crianças com idade entre 7 a 15 anos, são 1.687 pessoas, representando 26,63\% do total, seguida das com idade entre 0 a 4 anos (14,84\%). Enquanto os grupos com menor frequência são de idosos entre 60 a 64 anos (1,22\%) e acima de 65 anos (0,65\%).

Tabela 7 - Distribuição das pessoas que compõem as famílias beneficiárias do PBF, por faixa etária

\begin{tabular}{lrr|rrr}
\hline Faixa etária & № Pessoas & $(\%)$ & Faixa etária & № Pessoas & $(\%)$ \\
\hline 0 a 4 anos & 940 & 14,84 & Entre 40 a 44 & 293 & 4,63 \\
Entre 5 e 6 & 472 & 7,45 & Entre 45 a 49 & 230 & 3,63 \\
Entre 7 e 15 & 1.687 & 26,63 & Entre 50 a 54 & 181 & 2,86 \\
Entre 16 a 17 & 285 & 4,50 & Entre 55 a 59 & 114 & 1,80 \\
Entre 18 a 24 & 725 & 11,45 & Entre 60 a 64 & 77 & 1,22 \\
Entre 25 a 34 & 930 & 14,68 & Maior que 65 & 41 & 0,65 \\
Entre 35 a 39 & 359 & 5,67 & & & $\mathbf{6 . 3 3 4}$ \\
\hline Total & \multicolumn{7}{c}{} \\
\hline
\end{tabular}

Fonte: Elaboração própria a partir do Cadastro Único (2018).

Essa distribuição pode ser interpretada devido à própria característica do programa, que visa beneficiar lares com crianças e pré-adolescentes. Os dados apresentados são similares aos revelados em estudo de Silva et al (2017), em que os autores constatam que, o número baixo de idosos beneficiários se justifica devido à acessibilidade ao sistema previdenciário que, muitas vezes, tira-os da condição de pobreza e, assim, de potenciais beneficiários do PBF.

\subsection{Estrutura dos domicílios}

Neste tópico, apresenta-se e discute-se alguns dados sobre as condições estruturais dos domicílios dos beneficiários do PBF, já que estas são indicadores interessantes da situação socioeconômica vivenciadas pelas famílias participantes do PBF. 
A Tabela 8 apresenta o material predominante nas paredes externas das casas dos beneficiários do PBF. No que se refere às condições de moradia, o material predominante nas paredes externas é de alvenaria (65,58\%), seguida pela madeira presente em 640 lares $(32,79 \%)$. A escolha por construções de alvenaria refere-se à durabilidade e segurança, apesar de serem mais caras em relação às casas de madeira, já que os beneficiários são indivíduos pobres. Santos (2017), afirmam que casas construídas em alvenaria proporcionam uma moradia mais resistente e segura.

Tabela 8- Domicílio das famílias beneficiárias do PBF, por material predominante nas paredes externas

\begin{tabular}{lrr|rrr}
\hline Material & Domicílios & $(\%)$ & Material & Domicílios & (\%) \\
\hline Alvenaria/ tijolo revestido & 1.062 & 54,41 & Mad. aproveitada & 203 & 10,40 \\
Alvenaria/ tijolo sem revestir & 218 & 11,17 & Palha & 0 & 0,00 \\
Madeira Aparelhada & 437 & 22,39 & Outro Material & 3 & 0,15 \\
Taipa Revestida & 1 & 0,05 & Sem informação & 27 & 1,38 \\
Taipa não revestida & 1 & 0,05 & & & \\
\hline Total de domicílios & & & $\mathbf{1 . 9 5 2}$ & $\mathbf{1 0 0 \%}$ \\
\hline
\end{tabular}

Fonte: Elaboração própria a partir do Cadastro Único (2018).

De acordo com Souza e Couto (2015), os beneficiários do PBF do estado do Paraná possuem domicílios predominantemente construídos em alvenaria, seguido por madeira. Os autores afirmam que a utilização da madeira como material principal na construção de casas é devido a uma questão de especificidade regional, ao contrário do Nordeste onde a predominância é de casas construídas em alvenaria, seguido por de outros materiais não especificados e em terceiro lugar a madeira.

A madeira aproveitada é também o material muito utilizado na região Sul e Norte do país, no entanto, segundo Camargo et al (2013) esse material é caracterizado pela precariedade habitacional dos beneficiários, de igual modo, a utilização de taipa, palha e outros materiais que representam na região Norte $24,5 \%$ dos domicílios dos beneficiários e na região Nordeste $20,1 \%$.

A Tabela 9 evidencia os materiais usados no revestimento do piso das residências. Constata-se que mais da metade dos pisos $(53,59 \%)$ são revestidos de cerâmica, lajota ou pedra. Em segundo lugar, a madeira emparelhada é o material que mais compõem o piso das residências, estando presente em 361 domicílios representando 18,49\% do total. 
Tabela 9 - Domicílio das famílias beneficiárias do PBF, por material predominante no piso

\begin{tabular}{lrr|crr}
\hline Material & Domicílios & $(\%)$ & Material & Domicílios & $(\%)$ \\
\hline Terra & 3 & 0,15 & Cerâmica, lajota, pedra & 1.046 & 53,59 \\
Cimento & 250 & 12,81 & Carpete & 1 & 0,05 \\
Madeira aproveitada & 254 & 13,01 & Outro Material & 3 & 0,15 \\
Madeira aparelhada & 361 & 18,49 & Sem informação & 27 & 1,38 \\
\hline Total de domicílios & \multicolumn{7}{c}{} & & $\mathbf{1 . 9 5 2}$ \\
\hline
\end{tabular}

Fonte: Elaboração própria a partir do Cadastro Único (2018).

Ainda sob a análise dos domicílios dos beneficiários do PBF, o próximo item de exame é a existência de banheiro nos lares dessas famílias. A Tabela 10 nos revela esses dados. São 1.893 famílias beneficiárias que possuem banheiro em suas residências, esse dado representa quase a totalidade das famílias (96,98\%). No entanto, ainda há 32 famílias que não possuem esse item $(1,64 \%)$.

Tabela 10 - Domicílio das famílias beneficiárias do PBF, por existência de banheiro

\begin{tabular}{lrr}
\hline Existência de Banheiro & № de domicílios & Percentual (\%) \\
\hline Sim & 1.893 & 96,98 \\
Não & 32 & 1,64 \\
Sem informação & 27 & 1,38 \\
\hline Total & $\mathbf{1 . 9 5 2}$ & $\mathbf{1 0 0 \%}$ \\
\hline
\end{tabular}

Fonte: Elaboração própria a partir do Cadastro Único (2018).

O último indicador analisado em relação aos domicílios refere-se à forma de abastecimento de água nos lares das famílias beneficiárias do PBF (Tabela 11). Conforme os dados, a forma de abastecimento de água predominante é a rede geral de distribuição, que está presente em 1.842 lares (94,36\%), seguida de poço ou nascente em 69 lares (3,53\%). Enquanto a cisterna é utilizada por apenas 1 família (0,05\%).

De acordo com o IBGE (2010), o abastecimento de água por meio de rede geral está relacionado a uma melhor infraestrutura, proporciona conforto e água tratada, enquanto as outras formas de abastecimento talvez a água não passe por nenhum processo de tratamento. Também há predominância de água encanada em outras regiões do país, na Bahia $70 \%$ dos domicílios dos beneficiários possuem acesso à rede geral (SOUZA; COUTO, 2015), igualmente em Viçosa/MG com 98,4\% dos lares (SOUZA et al., 2012). Sob um ponto de vista regional encontrase disparidades, enquanto as regiões Sudeste, Sul e Centro-Oeste possuem aproximadamente $80 \%$ de domicílios com água encanada, as regiões Norte e Nordeste possuem menores proporções (CAMARGO et al., 2013). Souza e Couto (2015) ressaltam que devido aos fatores climáticos, a escassez de água nas regiões Norte e Nordeste é muito comum a população recorrer ao uso de cisternas para coletar e armazenar água da chuva. 
Tabela 11 - Domicílio das famílias beneficiárias do PBF, forma de abastecimento de água

\begin{tabular}{lrr}
\hline Abastecimento de água & № de domicílios & Percentual (\%) \\
\hline Rede Geral & 1.842 & 94,36 \\
Poço ou nascente & 69 & 3,53 \\
Cisterna & 1 & 0,05 \\
Outra forma & 13 & 0,76 \\
Sem informação & 27 & 1,38 \\
\hline Total & $\mathbf{1 . 9 5 2}$ & $\mathbf{1 0 0 \%}$ \\
\hline
\end{tabular}

Fonte: Elaboração própria a partir do Cadastro Único (2018).

Em suma, os beneficiários do PBF em Pato Branco/PR possuem razoáveis indicadores em relação as condições de moradia. As famílias residem em casas em que o material de construção predominante é a alvenaria ou a madeira, além de possuir água tratada e banheiro. Itens esses, básicos e considerados essenciais quanto à qualidade de moradia e infraestrutura, bem como para uma qualidade mínima e digna de vida das pessoas.

\subsection{Renda e acesso ao trabalho remunerado}

Esta seção fecha a parte da análise dos dados apresentando indicadores de renda (per capita) e da situação laboral dos atores sociais que são beneficiados pelo PBF, informações essenciais para conhecer-se o perfil econômico da população alvo da política social.

A Tabela 12 traz a faixa de renda per capita das famílias beneficiarias do PBF. Os dados mostram que mais da metade dessas famílias possui uma renda entre $R \$ 85,01$ a $R \$ 170,00$, sendo um número de 1.062 famílias, representando 54,41\% dos beneficiários. Isso representa um rendimento entre $8,91 \%$ a $17,81 \%$ do salário mínimo nacional vigente de $\mathrm{R} \$ \mathbf{9 5 4 , 0 0}$. Seguida por rendas mais baixas, 597 famílias beneficiárias (30,58\%), possuem renda per capita de até R\$ 85,00 , o que representa apenas $8,9 \%$ do salário mínimo a época. Se somados estes dois percentuais, quase $85 \%$ das famílias auferem, per capita, até $\mathrm{R} \$ 170,00 / \mathrm{mês}$, evidenciando a situação de vulnerabilidade social que estes atores vivem. Não obstante, nenhuma família possui renda acima de meio salário mínimo.

Tabela 12 - Perfil das famílias do PBF, por faixa de renda per capita

\begin{tabular}{lrr}
\hline Renda per capita & № de famílias & Percentual (\%) \\
\hline Até $\mathrm{R} \$ \mathrm{85,00}$ & 597 & 30,58 \\
De $\mathrm{R} \$ 85,01$ a R\$ 170,00 & 1.062 & 54,41 \\
De $\mathrm{R} \$ 170,00$ a $1 / 2$ salário & 293 & 15,01 \\
Acima de $1 / 2$ salário & 0 & 0,00 \\
\hline Total & $\mathbf{1 . 9 5 2}$ & $\mathbf{1 0 0 \%}$ \\
\hline
\end{tabular}

Fonte: Elaboração própria a partir do Cadastro Único (2018). 
Espinola (2013) afirma que o salário mínimo estabelecido pelo Governo Federal não é suficiente para atender as necessidades consideradas básicas de uma família, sequer para a garantia de segurança alimentar, considerados os preços dos alimentos. Dados do IPEA (2006) revelam que a quantidade de indivíduos que auferem renda aproximada a um salário mínimo é muito baixa. Dentre as famílias pobres brasileiras, menos de $15 \%$ têm um empregado com rendimento próximo a um salário mínimo, menos de $10 \%$ desses vivem em famílias extremamente pobres e $30 \%$ em famílias pobres e apenas $22 \%$ com rendimento aproximado de um salário mínimo são chefes de famílias pobres.

As regiões mais ricas economicamente do país (Sudeste, Sul e Centro-Oeste), possuem uma distinta distribuição de renda per capita entre os beneficiários em relação ao Nordeste e Norte. Os beneficiários em situação de extrema pobreza (renda até $\mathrm{R} \$ \mathbf{8 5}, 00$ ) estão distribuídos na região Nordeste com $82,2 \%$, enquanto na região Sul a participação é $54 \%$, em que no estado do Paraná, a maior distribuição é de beneficiários com baixa renda (R\$170,00 a meio salário mínimo) representando 34,49\% (CAMARGO et al., 2015; SOUZA; COUTO, 2015).

A identificação de indivíduos acometidos pela pobreza - sob uma perspectiva econômica - é realizada mediante a determinação de um dado nível de renda. Desse modo, são rotulados como indigentes, miseráveis ou extremamente pobres aqueles cuja renda é insuficiente para satisfazer as necessidades básicas para subsistência (ESPINOLA, 2013). No entanto, de acordo com Sen (2000), a pobreza não deve ser definida apenas como um valor auferido abaixo de um patamar estabelecido, mas também considerada como uma privação de obter condições básicas para existência enquanto indivíduo. Sob essa lógica, “o aumento da renda pode ter papel importante para o desenvolvimento de capacitações, como também pode ser resultado de desenvolvimento". Assim, a falta de capacitações pessoais possui associação direta com a baixa renda individual ou familiar (AZEVEDO, 2017, p. 47).

A Tabela 13 apresenta os dados de empregabilidade dos representantes familiares no último ano (12 meses). Ela retrata que 1.012 representantes familiares (51,84\%) não possuíram trabalho remunerado nos últimos 12 meses, evidenciando a precariedade social empregatícia existente nas famílias. Outras 940 representantes das famílias $(48,16 \%)$ receberam algum dinheiro proveniente de trabalho nos últimos 12 meses. Os representantes familiares que não possuem rendimentos provenientes de trabalho há mais de 12 meses, atingem 1.845 pessoas que compõem essas famílias. Ficar sem trabalho remunerado é bastante delicado para a preservação do tecido social, já apenas o recebimento do benefício não é suficiente para o 
atendimento das necessidades básicas demandas por uma família em situação de pobreza (alimentação, vestuário, transporte, pagamento de água e energia elétrica, remédios, entre outros gastos existentes).

Tabela 13 - Perfil dos responsáveis familiares do PBF, por trabalho remunerado (12 meses)

\begin{tabular}{lrr}
\hline Trabalho remunerado/12 meses & № de famílias & Percentual (\%) \\
\hline Sim & 940 & 48,16 \\
Não & 1.012 & 51,84 \\
\hline Total & $\mathbf{1 . 9 5 2}$ & $\mathbf{1 0 0 \%}$ \\
\hline
\end{tabular}

Fonte: Elaboração própria a partir do Cadastro Único (2018).

Críticos do PBF argumentam que essa política de transferência de renda desmotiva os pobres a procurar emprego e buscar qualificação profissional, o que os torna dependentes do auxílio (PEÑA et al., 2015). Segundo Medeiros, Brito e Soares (2007), a crítica está baseada na ideia, de que, à medida que o beneficiário atinge certo nível de renda, teria incentivo para trabalhar menos ou deixar de trabalhar. No entanto, os autores reconhecem essa crítica como mal fundamentada, visto que o valor da transferência recebido é tão baixo que não parece suficiente para que o beneficiário deixe de trabalhar ou de buscar atividades remuneradas mais estáveis.

Rabelo (2011) afirma que há evidencias de que beneficiários preferem um emprego ou melhorar sua renda ao invés de depender economicamente apenas do recebimento do benefício. O autor aponta os estudos de Marques (2006) e Marques e Rocha (2007), em que beneficiários exemplificam a preferência por um emprego e ressaltam o sentimento recompensador que o trabalho trás, sentem-se valorizados como pessoa e cidadão.

\section{Considerações finais}

A contribuição dos programas de transferência de renda condicionada apresenta uma avaliação positiva, especialmente no que se refere ao enfrentamento das desigualdades sociais. No caso do PBF, o programa tem apresentado bons resultados no município, que de maneira geral, já possui indicadores sociais e econômicos bons, embora, exista quase $6,5 \%$ da população local em situação de vulnerabilidade social, pois integram o Cadúnico municipal, evidenciando as contradições que ocorrem nos processos de desenvolvimento local.

A pesquisa nos revela o perfil dos beneficiários do PBF onde os dados apontam que grande parte destes reside em áreas urbanizadas e estão em sua maioria distribuídos na região 
Oeste e Sul do município. Mais da metade dos beneficiários são do sexo feminino $(58,76 \%$ dessas pessoas são mulheres), cumprindo o que preza as normas do PBF, em destinar os recursos para serem administrados por estas, que gestionam melhor as famílias e as condições de vida dos filhos como os estudos têm revelado.

Também chama a atenção a maioria dos beneficiários possuírem baixa escolaridade e poucas oportunidades de trabalho remunerado, duas condições que impossibilitam seu pleno desenvolvimento com liberdade, como Amartya Sen preconiza. Para tanto, a educação e a inserção nos mercados de trabalho formais precisam continuar sendo alvos de outras políticas públicas para além do PBF, para contribuir com a inserção laboral e econômica-produtiva desses atores sociais vulneráveis. Os estudos citados ao longo da análise demonstram que o PBF vem ampliando as liberdades da população na medida em que garante maior autonomia às mulheres, maior escolarização e maiores níveis de saúde à população. O PBF cria condições mínimas para que as capacidades individuais possam ser desenvolvidas e serem aplicadas na geração de renda e para interromper o ciclo da pobreza nas gerações futuras.

No que tange a qualidade dos domicílios das famílias beneficiárias do PBF, grande parte das residências está em boas condições de infraestrutura, pois eles possuem acesso à água encanada e tratada, pisos revestidos e a moradia na maioria das famílias é de alvenaria, embora, algumas residências ainda não disponham de banheiro.

A partir de uma análise multidimensional da pobreza, entende-se que o PBF define a pobreza apenas como insuficiência monetária, sendo esta ideia limitada, dado que somente as transferências monetárias não resolverão esta situação. Nesse sentido, a abordagem das capacidades humanas fornece subsídios para que uma política de combate à pobreza não deva ter como único objetivo os aspectos econômicos. Logo, para romper a pobreza são necessárias políticas públicas integradas e em diferentes níveis territoriais (local, regional, estadual e nacional) que eliminem as causas das privações de liberdades dessa população vulnerável.

\section{Referências}

AZEVEDO, V. R. Políticas públicas e abordagem das capacitações: uma análise do Programa Bolsa Família a partir do censo 2010. 2017, 149f. Dissertação de mestrado. Programa de PósGraduação em Economia e Desenvolvimento. Universidade Federal de Santa Maria: 2017. BICHIR, R. M. O Bolsa Família na Berlinda? Os desafios atuais dos programas de transferência de renda. Novos Estudos, p. 115-129, Jul 2010.

BRASIL. Decreto no 9.160 de 26 de setembro de 2017. Institui o Plano Progredir. Diário Oficial, Brasília, DF, 24 set. 2017. 
BRASIL. Decreto no 4.102, de 24 de janeiro de 2002. Regulamenta a Medida Provisória no 18, de 28 de dezembro de 2001, relativamente ao "Auxílio-Gás". Diário Oficial, Brasília, DF, 24 jan.

2002.

BRASIL. Ministério da Saúde. Programa alimentação saudável: bolsa-alimentação. Diário Oficial, Brasília, 2002. Disponivel em: <http://bvsms.saude.gov.br/bvs/publicacoes/

alimenta_saudavel.pdf $>$. Acesso em: 14 julho 2018.

BRASIL. Ministério do Desenvolvimento Social e Combate à Fome. O Brasil sem Miséria. Tereza Campello, Tiago Falcão, Patrícia Vieira da Costa (orgs). Brasília: MDS, 2014

BRASIL. Ministério do Desenvolvimento Social e Combate à Fome. Relatório Bolsa Família, 2018. Disponivel em: <http://mds.gov.br/bolsafamilia>. Acesso em: 14 julho 2018.

BRASIL. Ministério do Desenvolvimento Social e Combate à Fome. RI Bolsa Família e Cadastro Único, 2018. Disponivel em: <https://aplicacoes.mds.gov.br/sagi/Rlv3/geral/relatorio.php>. Acesso em: 14 julho 2018.

BRITO, F.; SOUZA, J. Expansão urbana nas grandes metrópoles: o significado das migrações intermetropolitanas e da mobilidade pendular na reprodução da pobreza. São Paulo em Perspectiva, São Paulo, v. 19, n. 4, p. 48-63, out/dez 2005.

BOISER, S. Desarollo (local): de qué estamos hablando? In: MADOERY, O.; VAZQUEZ BARQUERO, A. (Eds.). Transformaciones globales, Instituciones y Políticas de desarrollo local. Rosario: Editorial Homo Sapiens, 2001.

CAMARGO, C. F. et al. Perfil Socioeconômico dos Beneficiários do Programa Bolsa Família: O que o cadastro único revela?. In: Campello, T; Neri, M. C. Programa Bolsa Família: Uma década de inclusão e cidadania. Brasília: IPEA, Cap. 9, p. 502, 2013.

CAMPELLO, T.; NERI, M. C. (Orgs.). Programa Bolsa Familia: uma década de inclusão e cidadania. Brasília: IPEA, 2013, 502p.

COSTANZI, R. N.; FAGUNDES, F. Perfil dos Beneficiarios do Programa Bolsa Família. In: CASTRO, J. A.; MODESTO, L. Bolsa Família 2003-2010: Avanços e desafios. Brasília: IPEA, v. 2, 2010. p. 336.

DE PAULA, A. M. N. R.; JÚNIOR, J. C. As migrações campo-cidade: os diferentes enfoques interpretativos. III Simpósio Nacional de Geografia Agrária, Presidente Prudente, p. 1-10, nov 2005.

DUARTE, G. B.; SAMPAIO, B.; SAMPAIO, Y. Programa Bolsa Família: impacto das transferências sobre os gastos com alimentos em famílias rurais. RESP, Piracicaba, v. 47, p. 903-918, out/dez 2009.

ESPINOLA, G. M. Bolsa Família: uma análise a partir da concepção dos beneficiários de São Felipe - BA. 2013. 143f. Dissertação de Mestrado. Programa de Pós-Graduação em Gestão de Políticas Públicas e Segurança Social. Universidade Federal do Recôncavo da Bahia. Cruz das Almas: 2013.

IBGE. INSTITUTO BRASILEIRO DE GEOGRAFIA E ESTATÍSTICA. Síntese de indicadores sociais. Uma análise das condições de vida da população brasileira. IBGE. Rio de Janeiro: 2010.

IPEA. Sobre a recente queda da desigualdade de renda no Brasil. Instituto de Pesquisa Econômica Aplicada, 2006. Disponivel em:

<http://www.ipea.gov.br/portal/images/stories/PDFs/nota_tecnica/2006_nt01_agosto_disoc.p df>. Acesso em: 15 julho 2018. 
IPEA. Uma agenda para o crescimento econômico e a redução da pobreza. Instituto de Pesquisa Econômica Aplicada, 2006. Disponível em: www.ipea.gov.br/portal/images /stories/PDFs/TDs/td_1234.pdf>. Acesso em: 10 novembro 2018.

MARTINS, A. P. B. Impacto do Bolsa Familia sobre a aquisição de alimentos em famílias brasileiras de baixa renda. 2013. 123f. Tese (Doutorado em Nutrição em Saúde Pública) Programa de Pós Graduação em Nutrição em Saúde Pública, Universidade de São Paulo, São Paulo, 2013.

MARQUES, A. Dimensões da autonomia: o Programa Bolsa-Família na mídia e na fala das beneficiárias. ALACIP, Campinas, 2006.

MARQUES, A; ROCHA, S. A política a partir das margens: a produção discursiva sobre o programa bolsa-família em grupos de discussão. Revista FAMECOS, n.32, p. 1-23, 2007.

MEDEIROS, M.; BRITTO, T.; SOARES, F. Transferência de renda no Brasil. Novos Estudos, p. 5-21, 2007.

MEDEIROS, B. T.; SANTOS, V. F. O perfil dos beneficiários do Programa Bolsa Família no município de Chapecó-SC. Revista Grifos, v. 40, p. 99-117, 2016.

MELO, H.P. Gênero e Pobreza no Brasil. Relatório final do Projeto Governabilidad Democrática de Género em America Latinay el Caribe. Brasília: CEPAL; SPM, 2005.

MOLYNEUX, M. Mothers at the Service of the New Poverty Agenda: Progresa/Oportunidades, Mexico's Conditional Transfer Programme. Social Policy \& Administration, v. 40, n. 4, aug. p. 425-449, 2006.

PATO BRANCO. Prefeitura Municipal. O Município. Disponivel em:

<http://www.patobranco.pr.gov.br/omunicipio/>. Acesso em: 13 julho 2018.

PEÑA, C. R. et al. A eficácia das transferências de renda: as tendências da desigualdade antes e depois do Programa Bolsa Família. Rev. Adm Pública, Rio de Janeiro, v. 29, p. 889-913, jul/ago 2015.

PNUD. Atlas do Desenvolvimento Humano do Brasil, 2013. Disponivel em: <http://www.atlasbrasil.org.br/2013/pt/perfil_m/2988>. Acesso em: 19 outubro 2018.

RABELO, M. M. O beneficiário do Programa Bolsa Família em Porto Alegre: perfis educacional e ocupacional. Indicadores Econômicos FEE, Porto Alegre, v. 38, n. 3, p.75-90, 2011.

SANTOS, T. L. et al. O perfil dos beneficiários e das famílias beneficiadas pelo Programa Bolsa Família no município de Ilhéus-Bahia. VII Semana do Economista, Ilhéus, p. 3-21, out/nov 2017.

SEN, A. K. Desenvolvimento como liberdade. Companhia de Letras, 2000

SILVA, C. B. D. C. et al. Perfil Socioeconômico dos Beneficiários Rurais do Programa Bolsa Família da Região Sul do Brasil. Análise Econômica, Porto Alegre, v. 35, p. 83-101, Jul 2017.

SILVA, M. O.; YASBEK, M. C.; DI GIOVANI, G. A. A política social brasileira no século XXI: a prevalência dos programas de transferência de renda. 3. ed. São Paulo: Cortez, 2007.

SILVA, O. D. S. O Bolsa Familia: Problematizando questões centrais da política de transferência de renda no Brasil. Ciência \& Saúde Coletiva, v. 12, p. 1429-1439, 2007.

SOUZA, N. et al. Perfil socioeconômico e insegurança alimentar e nutricional de famílias beneficiárias do Programa Bolsa Família no município de Viçosa, Estado de Minas Gerais, Brasil, em 2011: um estudo epidemiológico transversal. Epidemiol. Serv. Saúde, v. 21, p. 655-662, 2012. 
SOUZA, A. A.; COUTO, C. L. Programa Bolsa Família: características e perfil da pobreza entre os beneficiários nos estados do Paraná e Bahia. Informe Gepec, Toleto, v. 19, n. 2, p. 41-56, jun/dez 2015. 